\title{
Bike-sharing as a possibility to support Vision Zero
}

\author{
Katarzyna Turon ${ }^{1, *}$, and Grzegorz Sierpiński ${ }^{2}$ \\ ${ }^{1}$ Silesian University of Technology, Faculty of Transport, Department of Automotive Vehicle \\ Construction, Krasińskiego 8 Street, 40-019 Katowice, Poland \\ ${ }^{2}$ Silesian University of Technology, Faculty of Transport, Department of Transport Systems \\ and Traffic Engineering, Krasińskiego 8 Street, 40-019 Katowice, Poland
}

\begin{abstract}
Cyclists as unprotected road users are one of the most vulnerable groups of travelers. In order to improve their safety, various activities are carried out. Interested results are presented in Mineta Transportation Institute (MTI) report - Report 12-54: Bike-sharing and Bicycle Safety from 2016. It points out that there are no fatalities among users of city bike sharing systems in the United States. Due to the growing interest in systems in Poland, authors focused on the analysis of aspects related to the safety of their use. The paper presents factors that affect the road traffic safety of bike-sharing users. Authors referred to international practices used in cities bike-sharing systems and presented bike-sharing systems as an opportunity to support the implementation of Vision Zero.
\end{abstract}

\section{Introduction}

Traveling with the use of a bicycle as a mean of transport is the second, after walking, the healthiest, most ecological and socially propagated form of movement $[1,2]$.

For cyclists, it is also one of the options to facilitate movement in city traffic with increased congestion and problems with finding a parking space $[3,4]$. In addition, it is also an alternative form of traveling, desired during implementing the concept of sustainable urban mobility or searching for attractive sustainable transport good practices [5-10].

Despite the excellent promotion and all the advantages of traveling with a bicycle, unprotected road users are one of the most vulnerable groups of road users [11]. Statistics indicate that cyclists in Poland during 2016 participated in 4737 road accidents in which 271 cyclists were killed [12]. What is more, number of accidents increased in comparison of 2015 about $2.2 \%$ [13]. Due to this, safety issues of cyclists are a priority in striving to improve their traffic situation [14].

Because in urban transport systems, in recent years have been appeared many shortterm rental bikes, authors focused on the analysis of aspects related to the safety of their use. The research paper presents factors and areas of activities that affect the road traffic safety of bike-sharing users. Reference has been made to international practices used in

\footnotetext{
${ }^{*}$ Corresponding author: katarzyna.turon@polsl.pl
} 
cities bike-sharing systems. On the other hand, bike-sharing systems were presented as an opportunity to support the implementation of Vision Zero. The examples presented in this paper can be used as a guide during the implementation of new bike-sharing systems.

\section{Bike-sharing systems}

Bike-sharing are services that operate in urban transport systems. Their operation allows to rent a bicycle for a short period of time. To rent a bike it is enough to register in a given system and often pay the required deposit [15]. The vehicle rental process usually takes place via a mobile application or via the website of the operator functioning in the selected city [15]. The fees for a ride are charged automatically after the rental from the user account that was given during registration [15].

Over the years, the concept of bike-sharing has been improved with the use of newly available information technologies. Due to this, there are various forms of bicycle pickup including e.g. using a magnetic card scanner, scanning a QR code or entering the code displayed in the application. There are also various forms of leaving the bike in the city - a classic form using a docking station or a form without a station (dockless bike-sharing).

It is currently said that the systems available in most cities are $4^{\text {th }}$ or $5^{\text {th }}$ generation systems [16-18]. This means that access to bicycles is possible via a mobile application, and it is also possible to monitor the availability and location of bikes in real time, and the systems themselves are often integrated thanks to the ITS traffic management technologies - 4th generation [17]. On the other hand, the most innovative 5th generation on the market makes it possible to leave bicycles anywhere in the city - so-called. non-contact systems [18]. Such a generation is also a tool that uses the opportunities offered by big data management [18].

\section{Bike-sharing in the context of safety}

It is very difficult to show the causal relationship between bike-sharing and vision zero in its pure form. However, it is important to try reduce number of accidents and facilities for each kind of mean of transport. Even small step in this process can support the final result of changes in transport safety - vision zero. Below, in the section, selected aspects of traffic safety in relation to biking were described. Some of them can be implement also in private bikes, but mostly are specific only for bike-sharing systems.

Based on the MTI report (Mineta Transportation Institute) in MTI Report 12-54: Bikesharing and Bicycle Safety, where it is mentioned that from 2010 to 2016 in the United States no fatalities were recorded among users of bike-sharing [19]; and also on the publications dedicated to the analysis of traffic safety data of bike-sharing systems [20] [21], describing the equipment of the systems [15,22] and on the authors' own experiences, were distinguished areas and specific factors according to which bike-sharing affects the safety of cyclists.

The first area is the construction of bicycles used for bike-sharing. The analysis used in world bicycle systems indicates that the rental bikes are heavier than classic ones [19]. In addition, the bikes are equipped with a thicker frame [19]. Thanks to these features, they become more stable and durable. Bicycles from bike-sharing are also equipped with specially designed gearboxes, which encourage users to slow down. It should also be mentioned that bicycles have a special type of tires [23]. These tires are wider, their surface provides less slip. In addition, it should be mentioned that the tires are more durable and better suited to riding in difficult urban conditions. Therefore for cycling on curbs, holes in the roadway, pavements in poor condition or tram tracks [24,25]. Suitable tires provide 
better contact with the ground, improve traction and riding safety, e.g. during rain.

Another of the design features is the provision of many bikes from bike-sharing rentals with lights that allow their increased visibility while cycling [19].

An additional element can also be bicycles shifter's containing information that will improve safety, e.g. information about the need to turn on the lights or a reminder to wear a helmet [19].

Another of the areas that improve the safety of bike-sharing is the use of additional equipment which can be a bicycle helmet. In the world there are operators who require their users to move in helmets [26]. For this purpose, additional boxes for helmet rental are placed next to the docking station for bicycles.

The appearance of bicycles is another of the areas supporting safety. Many operators try to make their bikes have bright colors, thanks to which the visibility of cyclists on the road is improved. An example of a yellow bicycle operator's fleet in Shanghai in China is shown in Figure 1.

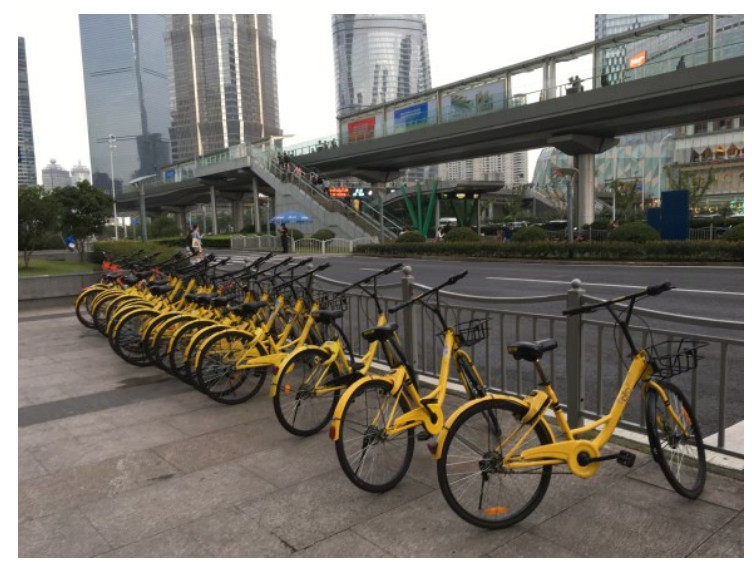

Fig. 1. Example of yellow bicycles, more visible to road users, in bike-sharing service, Shanghai, China (Source: author's own collaboration).

In addition, in order to increase the visibility of bike-sharing bikes at night or in cloudy weather, operators decide to place fluorescent elements on bicycles or cover the bike's construction with fluorescent paint. An example of a bike coming from bike-sharing and its visibility at dusk is presented in Figure 2.

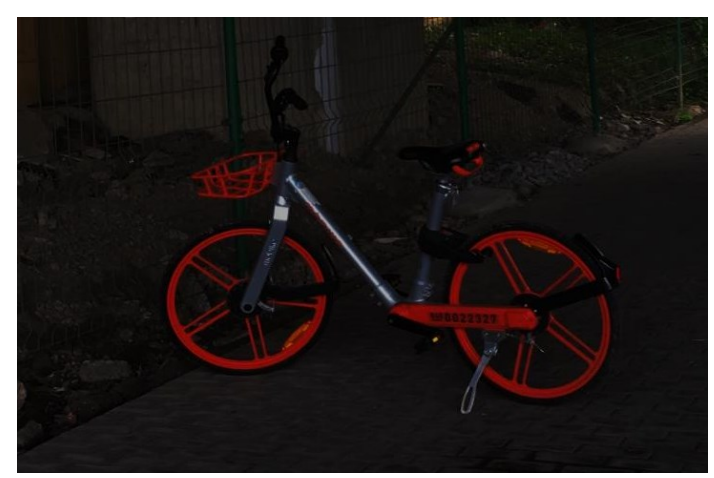

Fig. 2. Example of bike-sharing bike with fluorescent elements for better visibility after the onset of darkness, Shanghai, China (Source: author's own collaboration)

The next of the areas affecting the safety of bike-sharing users includes the use of bicycle systems. In many cases, the use of the system involves the payment of an 
appropriate deposit for the bike used. Research shows that this type of activity increases the alertness and attentiveness of users when using bike-sharing systems [19].

Cycling locations can also be improved by the location of the docking stations. These places are usually found in limited speed zones and where there are many pedestrians. Then, the cyclists themselves must be more careful when moving. Also more bikes from bike-sharing on the road affect the more cautious behavior of drivers and accustom them to situations where they are not alone on the road [19]. It should also be mentioned here that cyclists using bike-sharing systems are usually less experienced than individual cyclists who use bicycles each day, so they behave more carefully and drive more slowly [20].

It is also worth mentioning that the development of bike-sharing contributes to increasing the investment of cities in cycling infrastructure, e.g. bike routes, bike paths, cycle tracks at roundabouts, bike lanes, which also contributes to improving road safety $[27,28]$.

In addition, it is also worth paying attention to other factors related to the safety of bikesharing, such as system operators organizing all actions promoting careful riding.

The list of aspects together with detailed factors influencing the particular area of bikesharing safety is presented in Table 1 .

Table 1. Aspects of bike-sharing safety along with detailed factors.

\begin{tabular}{|c|c|}
\hline $\begin{array}{l}\text { Aspect that } \\
\text { affects safety }\end{array}$ & Characterization of factors \\
\hline $\begin{array}{l}\text { Construction of } \\
\text { bicycles } \\
\text { to bike-sharing }\end{array}$ & $\begin{array}{l}\text { - } \text { bikes are heavier than classic, } \\
\text { - } \quad \text { bikes got thicker frames than classic, } \\
\text { - } \text { bikes got stable and more durable construction, } \\
\text { - } \text { bikes have gearboxes designed in such a way to drive them slower, } \\
\text { - } \quad \text { bikes got wider, anti-slip tires adapted to bumpy roads, curbs and tram lines, } \\
\text { - } \text { special tires construction provide better surface traction, } \\
\text { - } \quad \text { many of bikes got included light and reflectors for increased visibility, } \\
\text { - } \quad \text { some bicycle operators, information appears to improve safety, for example } \\
\text { information on the need to turn on the lights or a reminder to wear a helmet } \\
\text { on the bicycle's grips, }\end{array}$ \\
\hline A & $\begin{array}{l}\text { some operators provide helmets to the users of their systems, ensuring their } \\
\text { head protection, }\end{array}$ \\
\hline Bike appearance & $\begin{array}{l}\text { - bike-sharing bikes usually have bright- fluorescent colours of frames and } \\
\text { elements to improve visibility road users, }\end{array}$ \\
\hline Syste & $\begin{array}{l}\text { - registering for the system requires payment of the deposit, which is why } \\
\text { cyclists are more attentive while riding, }\end{array}$ \\
\hline $\begin{array}{c}\text { Location of } \\
\text { docking stations }\end{array}$ & $\begin{array}{l}\text { - the location of docking stations is usually in zones where there is a redu } \\
\text { speed and more pedestrians which results in greater mindfulness of cycli }\end{array}$ \\
\hline $\begin{array}{l}\text { The impact of } \\
\text { bike-sharing on } \\
\text { the urban } \\
\text { transport system }\end{array}$ & $\begin{array}{l}\text { - more bikes on the road, thanks to the fact that they are made available by } \\
\text { rental companies, increase the mindfulness of drivers and require them to } \\
\text { adapt to the fact that they are not on their way, } \\
\text { - with the increasing popularity of renting bicycles in cities, there is more and } \\
\text { more cycling infrastructure, } \\
\text { - cyclists using public bikes are usually less experienced, and therefore more } \\
\text { cautious, they are going more carefully and slowly, }\end{array}$ \\
\hline Safety promotion & $\begin{array}{l}\text { hat promote safe } \\
\text { s. }\end{array}$ \\
\hline
\end{tabular}

Source: author's own collaboration based on $[15,16,19,20,26-30]$.

It should be mentioned that the bike-sharing solution as well as any new transport concept, apart from so many advantages presented in the text, also has disadvantages. The main disadvantage of every sharing system users may be the lack of experience that 
individual users may have [29,30]. This may cause traffic hazards due to poor knowledge of regulations or just uncertain maneuvers. In addition, public bicycles are not personalized under each user individually, which can also cause a traffic hazard. It is also worth paying attention to the technical aspect. Due to the safety of users, it is worth checking the equipment of bicycles and their technical condition. Because many people use part of the "sharing" solutions, parts wear out, which can reduce safety while driving [31]. It is also worth paying attention to the technical aspect. Due to the safety of users, it is worth checking the equipment of bicycles and their technical condition. Because many people use part of the "sharing" solutions, parts wear out, which can reduce safety while driving. In addition, a significant disadvantage may also be the additional protection of bicycles because, as public goods, they may be subject to theft and the lack of some equipment may significantly affect the safety of system users as well as other road users.

\section{Summary and further research}

The results of the research shown that the elements of bike-sharing systems could got the impact of improving the level of safety in urban transport systems, but to achieve a greater level of safety in bike-sharing systems, it is important to focus on security issues already at the design stage of systems and to motivate users to use the systems accordingly. The article shown that bike-sharing systems could be one of the possibilities to support the Vision Zero. The examples presented in this paper can be used as a guide during the implementation of new bike-sharing systems or during improving the existing systems safety level.

As further research Authors plans to make study about the visibility of bike-sharing bikes. It needs cooperation with some bike-sharing operators to test in real different colors of bikes.

\section{References}

1. T. Götschi, J. Garrard, B. Giles-Corti, Cycling as a Part of Daily Life: A Review of Health Perspectives, Transp. Rev. 36 pp. 45-71 (2016). doi:10.1080/01441647.2015.1057877

2. R. Okraszewska, K. Nosal, G. Sierpiński, The role of the Polish universities in shaping a new mobility culture - assumptions, conditions, experience. Case study of Gdansk University of Technology, Cracow University of Technology and Silesian University of Technology, in: 7th Int. Conf. Educ. Res. Innov., pp. 2971-2979 (Seville, 2014)

3. E. Taniguchi, R.G. Thompson, T. Yamada, Recent Trends and Innovations in Modelling City Logistics, Procedia - Soc. Behav. Sci. 125 pp. 4-14 (2014). doi:10.1016/J.SBSPRO.2014.01.1451

4. K. Turoń, D. Golba, P. Czech, The analysis of progress CSR good practices areas in logistic companies based on reports \&quot;Responsible Business in Poland: good practices\&quot; in 2010-2014, Sci. J. Silesian Univ. Technol. Ser. Transp. 89 pp. $163-$ 171 (2015). doi:10.20858/sjsutst.2015.89.17

5. R. Okraszewska, K. Grzelec, K. Jamroz, Developing a cycling subsystem as part of a sustainable mobility strategy: the case of Gdansk, Sci. J. Silesian Univ. Technol. Ser. Transp. 92 pp. 87-99 (2016). doi:10.20858/sjsutst.2016.92.9

6. G. Sierpiński, M. Staniek, I. Celiński, New methods for pro-ecological travel behaviour learning, in: 8th Int. Conf. Educ. Res. Innov., pp. 6926-6933 (IATED, 
Seville, 2015)

7. K. Turoń, G. Sierpiński, P. Czech, Mobility in the scope of sustainable development challenges for urban transport systems, Traffic Eng. 1 pp. 53-57 (2018)

8. M. Jacyna, M. Wasiak, K. Lewczuk, M. Kłodawski, Simulation model of transport system of Poland as a tool for developing sustainable transport, Arch. Transp. . 31 (2014). doi:10.5604/08669546.1146982

9. R. Okraszewska, A. Romanowska, M. Wołek, J. Oskarbski, K. Birr, K. Jamroz, R. Okraszewska, A. Romanowska, M. Wołek, J. Oskarbski, K. Birr, K. Jamroz, Integration of a Multilevel Transport System Model into Sustainable Urban Mobility Planning, Sustainability. 10 pp. 479 (2018). doi:10.3390/su10020479

10. I. Jacyna-Gołda, Decision-making model for supporting supply chain efficiency evaluation, Arch. Transp. 33 pp. 17-31 (2015). doi:10.5604/08669546.1160923

11. L. Kania, Niechronieni użytkownicy ruchu (piesi, rowerzyści), Inżynieria Ruchu Drog. 3 pp. $46-49$ (2012)

12. Road accidents in Poland in 2016. Report of General Police Headquarters of Poland (Warsaw, 2017)

13. Road accidents in Poland in 2015. Report of General Police Headquarters of Poland (Warsaw, 2016)

14. E. Macioszek, D. Lach, Analysis of the results of General Traffic Measurements in the West Pomeranian voivodeship from 2005 to 2015, Sci. J. Silesian Univ. Technol. Ser. Transp. 97 pp. 93-104 (2017). doi:https://doi.org/10.20858/sjsutst.2017.97.9

15. P. Czech, K. Turoń, R. Urbańczyk, Bike-Sharing as an Element of Integrated Urban Transport System, in: Adv. Solut. Transp. Syst. Grow. Mobility. 14th Sci. Tech. Conf. “Transport Syst. Theory Pract. 2017”. Sel. Pap. Ed. by Eds. Grzegorz Sierpiński, pp. 103-111 (Springer, Cham, 2018). doi:10.1007/978-3-319-62316-0_8

16. S.A. Shaheen, S. Guzman, H. Zhang, Bikesharing in Europe, the Americas, and Asia, Transp. Res. Rec. J. Transp. Res. Board. 2143 pp. 159-167 (2010). doi:10.3141/214320

17. T. Mátrai, J. Tóth, Comparative Assessment of Public Bike Sharing Systems, Transp. Res. Procedia. 14 pp. 2344-2351 (2016). doi:10.1016/J.TRPRO.2016.05.261

18. Nextbike, Bike Sharing, Five Generations Later: What's next?, in: 2017 Annu. P. Conf., (Brussels, 2017)

19. E. Martin, A. Cohen, J. Botha, S. Shaheen, MTI Report 12-54: Bikesharing and Bicycle Safety (Mineta Transportation Institute, 2016)

20. E. Fishman, P. Schepers, Global bike share: What the data tells us about road safety, J. Safety Res. 56 pp. 41-45 (2016). doi:10.1016/J.JSR.2015.11.007

21. A.C. Kristianssen, R. Andersson, M.-Å. Belin, P. Nilsen, Swedish Vision Zero policies for safety - A comparative policy content analysis, Saf. Sci. 103 pp. 260-269 (2018). doi:10.1016/J.SSCI.2017.11.005

22. R. Okraszewska, Technical and organizational challenges of development of PublicUse Bicycles (PUBs), Logistyka. 4 pp. 3111-3117 (2014)

23. The Guardian, The 8 best cycling innovations: from dockless bikes to solid tyres. Available at: https://www.theguardian.com/cities/2017/jun/17/10-best-cyclinginnovations-dockless-bikes-solid-tyres. Accessed: 2018-04-04, (2018)

24. K. Turoń, P. Czech, M. Juzek, The concept of a walkable city as an alternative form of urban mobility, Sci. J. Silesian Univ. Technol. Ser. Transp. 95 pp. 223-230 (2017). doi:https://doi.org/10.20858/sjsutst.2017.95.20 
25. M. Staniek, Road pavement condition as a determinant of travelling comfort, in: G. Sierpiński (Ed.), Adv. Intell. Syst. Comput., pp. 99-107 (Springer, Cham, 2017). doi:10.1007/978-3-319-43991-4_9

26. PSFK Portal, Helmet Rental Vending Machines Keep Bikers Safe On-The-Go. Available at: https://www.psfk.com/2013/05/boston-helmet-rental-vendinmachine.html?utm_source $=$ Sailthru\&utm_medium $=$ email\&utm_term $=$ vertical_retail \&utm_campaign= vertical - Retail 2013-06-03. Accesse, (n.d.)

27. J. Pucher, R. Buehler, Cycling towards a more sustainable transport future, Transp. Rev. 37 pp. 689-694 (2017). doi:10.1080/01441647.2017.1340234

28. C.C. Reynolds, M.A. Harris, K. Teschke, P.A. Cripton, M. Winters, The impact of transportation infrastructure on bicycling injuries and crashes: a review of the literature, Environ. Heal. 8 pp. 47 (2009). doi:10.1186/1476-069X-8-47

29. F. Chen, K. Turoń, M. Kłos, P. Czech, W. Pamuła, G. Sierpiński, Fifth generation of bike-sharing systems - examples of Poland and China, Sci. J. Silesian Univ. Technol. Ser. Transp. 99 pp. 5-13 (2018). doi:10.20858/sjsutst.2018.99.1

30. K. Turoń, Car-sharing problems - multi-criteria overview, in: Proc. Fourth Int. Conf. Traffic Transp. Eng. ICTTE 2018, pp. 916-922 (Belgrade, 2018)

31. A. Kubik, K. Turoń, Z. Stanik, Car-sharing systems vehicles versus taxis in urban transport system - legal requirements, technical service, operation, in: Proc. Fourth Int. Conf. Traffic Transp. Eng. ICTTE 2018, pp. 923-930 (2018) 